${ }^{16}$ Liebow, I M, Hellestein, $\mathrm{H} \mathrm{K}$, and Miller, M, American Fournal of Medicine, 1955, 18, 438.

17 Keen, H, et al, Lancet, 1962, 2, 1188

18 Cohen, A M, Geriatrics, 1968, 23, 158

19 Garcia, M J, et al, Diabetes, 1974, 23, 105.

20 New, M I, et al, Diabetes, 1963, 12, 208.

${ }^{21}$ Levy, R I, and Glueck, C J, Annals of Internal Medicine, 1969, 123, 220.

${ }^{22}$ Wilson, D E, et al, Fournal of Chronic Diseases, 1970, 23, 501.

23 Ononogbu, I C, and Lewis, B, Clinica Chimica Acta, 1976, 71, 397.
${ }^{24}$ Burstein, M, Scholnick, H R, and Morfin, R, fournal of Lipid Research, 1970, 11, 583.

${ }^{25}$ Cramp, D C, and Robertson, G, Analytical Biochemistry, 1968, 25, 246 ${ }^{26}$ Miller, G J, Miller, N E, and Ashcroft, M T, Clinical Science and Molecular Medicine, 1976, 51, 475.

${ }^{27}$ Metropolitan Life Insurance Company, in Documenta Geigy, 7th edn, p 712. Macclesfield, Geigy Pharmaceuticals, 1970.

(Accepted 18 fanuary 1978)

\title{
Lung function in asthmatic children after year or more without symptoms or treatment
}

\author{
K F KERREBIJN， A C FIOOLE， R D W VAN BENTVELD
}

\begin{abstract}
Summary and conclusions
Lung function was examined in 24 children who for a year or more had not received treatment for asthma or had any asthmatic symptoms. Although clinical recovery from asthma was apparent, increased bronchial smoothmuscle tone remained present, which probably renders such children susceptible to obstructive lung disease in adult life. These children should be given guidance on treatment of their symptoms and instructed in preventive measures.
\end{abstract}

\section{Introduction}

Many doctors and patients consider that children have "grown out of" their asthma when their symptoms have disappeared and peak flow rates or spirometric values are within the normal range. Although abnormal respiratory function may be found in asthmatic people during symptom-free intervals, ${ }^{1-3}$ little is known about respiratory function in asthmatic children who have been symptom-free for a long period and are considered by everyone to be cured. We investigated respiratory function in children with a past history of asthma who had had no symptoms for 12 months or longer to see whether they were, in fact, cured.

\section{Patients and methods}

Respiratory function was measured in 24 children aged 9-16 (mean 12) years who had at some time received treatment in the outpatient department for respiratory diseases resulting from asthma. They were considered to be cured because $(a)$ for at least 12 months they had been free of cough, wheezing, and breathlessness at rest and on exertion and had not needed treatment for respiratory diseases; and $(b)$ over the past 12-18 months all three or more measurements of $\mathrm{FEV}_{1} / \mathrm{VC}$ (forced expiratory volume in one second expressed as percentage of inspiratory vital capacity) had been at least $70 \%$-that

\footnotetext{
Department of Paediatrics, Subdepartment of Respiratory Diseases, Erasmus University Medical School, Sophia Children's Hospital, Rotterdam, The Netherlands

$\mathrm{K}$ F KERREBIJN, MD, associate professor of respiratory diseases in children

A C FIOOLE, medical student

$R$ D W VAN BENTVELD, medical student
}

is, within $-2 \mathrm{SD}$ of the expected mean. $\mathrm{An} \mathrm{FEV}_{1} / \mathrm{VC}$ of below $70 \%$ is a sensitive indicator of bronchial obstruction ${ }^{45}$ and is easy to distinguish from normal values. The test is commonly used clinically and in epidemiological studies. All measurements were done on the same day between $9 \mathrm{am}$ and $1 \mathrm{pm}$, some of the children having been trained in advance. For ethical reasons we could not make comparative measurements in children without a history of asthma.

The following determinations were used in evaluating the results:

(1) Volume-constant body plethysmography (the body box; Siemens Siregnost FD 40) was used to measure total lung capacity $\left(\mathrm{TLC}_{\mathrm{Bb}}\right)$, functional residual capacity $\left(\mathrm{FRC}_{\mathrm{Bb}}\right)$, and residual volume $\left(\mathrm{RV}_{\mathrm{Bb}}\right)$. Volumes were calculated by integrating the expiratory flow through a heated pneumotachygraph (Fleisch No 31458), which is about linear up to $500 \mathrm{l} / \mathrm{min}$. The means of five to eight reliable determinations were used in each case. Measurements were taken with the patient sitting.

(2) Total lung capacity ( TLC $_{\mathrm{He}}$ ) was measured by the helium dilution method with a Mijnhardt volumograph (No 660502). The oxygen supply of this apparatus is controlled by the oxygen pressure in the helium and oxygen reservoir. Measurements were taken with the patient semirecumbent, the wash-in time being about 10 minutes. Means of duplicate measurements were used.

(3) VC, forced expiratory vital capacity (FVC), $\mathrm{FEV}_{1}$, and maximal mid-expiratory flow between $25 \%$ and $75 \%$ of FVC (MMEF) were measured with a valveless, 6 litre, waterfilled spirometer (Lode No D 53R). Measurements were taken with the patient sitting. The best of three values was used. VC was also measured in the body plethysmograph and from determinations of TLC $_{\mathrm{He}}$ and FVC with maximal expiratory flows (see below).

(4) Maximal expiratory flows were measured at $60 \% \mathrm{TLC}_{\mathrm{B}}$ $\left(\mathrm{MEF}_{60 \mathrm{TLC}}\right), 50 \%$ FVC $\left(\mathrm{MEF}_{50 \mathrm{FVC}}\right)$, and $25 \% \mathrm{FVC}\left(\mathrm{MEF}_{25 \mathrm{FVC}}\right)$ -that is, after $40 \%$ TLC, $50 \%$ FVC, and $75 \%$ FVC had been exhaled respectively. Measurements were taken sitting, outside the body plethysmograph, the child exhaling maximally through a heated pneumotachygraph. An artefact of this method, which is due to thoracic gas compression ${ }^{1}$ and affects the maximal expiratory flow curves, ${ }^{6}$ was ignored. A decrease indicated obstruction in the peripheral airways. ${ }^{7}$

All measurements were taken before and after bronchodilatation with intramuscular thiazinamium $25 \mathrm{mg}$. (Thiazinamium is a parasympatholytic drug with antihistaminic properties that causes maximal relaxation of the bronchial musculature.) The order of measurements before bronchodilatation was (3), (2), (4), and (1); after bronchodilatation this was reversed so that the $\mathrm{TLC}_{\mathrm{Bb}}$ did not increase because of swallowed air. Each series of measurements lasted about 90 minutes, and the patients rested for 15-30 minutes before and after the administration of thiazinamium.

The estimated mean values (EMV) were calculated with the regression equations of Zapletal et al. ${ }^{8}$ Accepted lower limits of the normal ranges are $80 \%$ of the EMV for TLC, VC, FVC, and FEV and $70 \%$ of the EMV for MMEF, $\mathrm{ME}_{60 \mathrm{TLC}}, \mathrm{MEF}_{50 \mathrm{FVC}}$, and $\mathrm{MEF}_{25 \mathrm{FVC}}$ - that is, about $-2 \mathrm{SD}$ of the EMV in all cases. Values for VC and FEV in healthy Dutch children ${ }^{9}$ and for MEF in Australian children $^{10}$ and a small series of healthy Dutch children investigated 
in our laboratory corresponded well with values found by Zapleta et al. The accuracy of all measurements was carefully checked. Comparison of vital-capacity measurements obtained with different equipment yielded correlation coefficients of 0.95 to 0.99 .

\section{Results}

Table I shows the mean results $( \pm S D)$ of respiratory function measurements before and after bronchodilatation as percentages of the EMV. Mean values of $\mathrm{MMEF}$ and $\mathrm{MEF}_{50 \mathrm{FvC}}$ bordered on normal; those of $\mathrm{MEF}_{60 \mathrm{TLC}}$ and $\mathrm{MEF}_{25 \mathrm{FVC}}$ were slightly lower than normal. Mean lung volumes changed little after bronchodilatation, whereas mean flows increased considerably. Individual values of $\mathrm{FEV}_{1}, \mathrm{MMEF}$, and $\mathrm{MEF}_{60 \mathrm{TLC}}$ were widely scattered and below normal in many children (see figure), as were values of $\mathrm{MEF}_{50 \mathrm{FVC}}$ and $\mathrm{MEF}_{25 \mathrm{FVC}}$. After bronchodilatation $\mathrm{MEF}_{60 \mathrm{TLC}}$ and $\mathrm{MEF}_{25 \mathrm{FVC}}$ were still low in six children, $\mathrm{MMEF}$ and $\mathrm{MEF}_{50 \mathrm{FVC}}$ were low in three, and $\mathrm{FEV}_{1}$ was low in one child.

TABLE I-Mean $( \pm S D)$ respiratory function values before and after bronchodilatation expressed as percentages of expected mean values

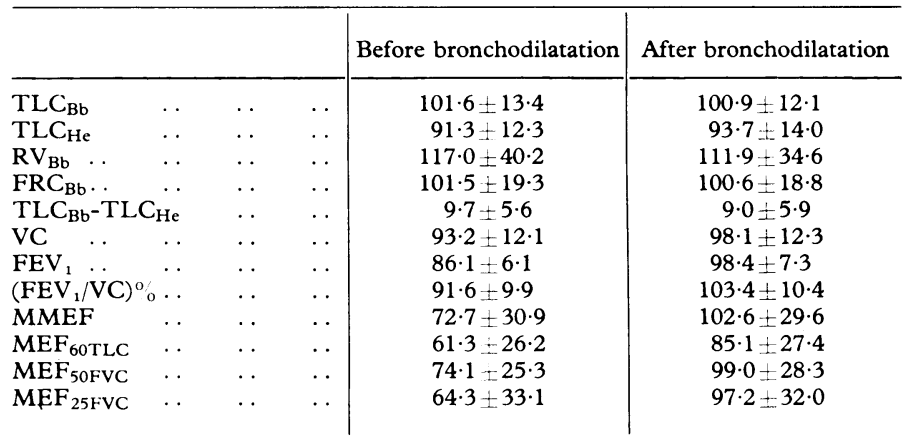

\section{Discussion}

These results show that although asthmatic symptoms in children may disappear for a long period, bronchial obstruction often remains. This conclusion is based on the mean and individual values for respiratory function and the improvement shown after bronchodilatation. The applied values for healthy children were important, and use of the mean values and normal ranges given by Zapletal et $a l^{8}$ seemed to be fully justified for Dutch children. We measured lung volumes and flows with the same type of body plethysmograph as that used by Zapletal et al.

Data on the enhancement of respiratory function in healthy children after thiazinamium are lacking. The effect on VC and $\mathrm{FEV}_{1}$ in our children was similar to that noted in healthy adults. ${ }^{11}$ In most healthy people there is no appreciable increase in expiratory flow rate after bronchodilatation, and sometimes a decrease occurs because of increased bronchial collapsibility resulting from relaxation of bronchial smooth muscle. ${ }^{12}$ This was seen in only a few of our children (see figure). In most asthmatic subjects, however, bronchodilator drugs noticeably increase the flow rate, ${ }^{12}$ and this was the case in most of our children. We therefore conclude that they had increased bronchial smooth-muscle tone in the peripheral airways. It would have been interesting to determine the reactivity of the airways to non-specific stimuli, ${ }^{13}$ which should have been decreased, but for several reasons this was not possible.

$\mathrm{FEV}_{1} / \mathrm{VC}$ seemed to be a less sensitive index of bronchial obstruction than $\mathrm{FEV}_{1}$ and the expiratory flows. Table II, which gives respiratory function data on 56 asthmatic children in a symptom-free period of at least one week, shows that $M M E F$ and $M E_{50 F v C}$ were of about equal sensitivity, as were $\mathrm{MEF}_{60 \mathrm{TLC}}$ and $\mathrm{MEF}_{25 \mathrm{FVC}} \mathrm{MEF}_{60 \mathrm{TLC}}$ and $\mathrm{MEF}_{25 \mathrm{FVC}}$ were the most sensitive indicators of bronchial obstruction. These findings agree with those of others. ${ }^{14-17}$
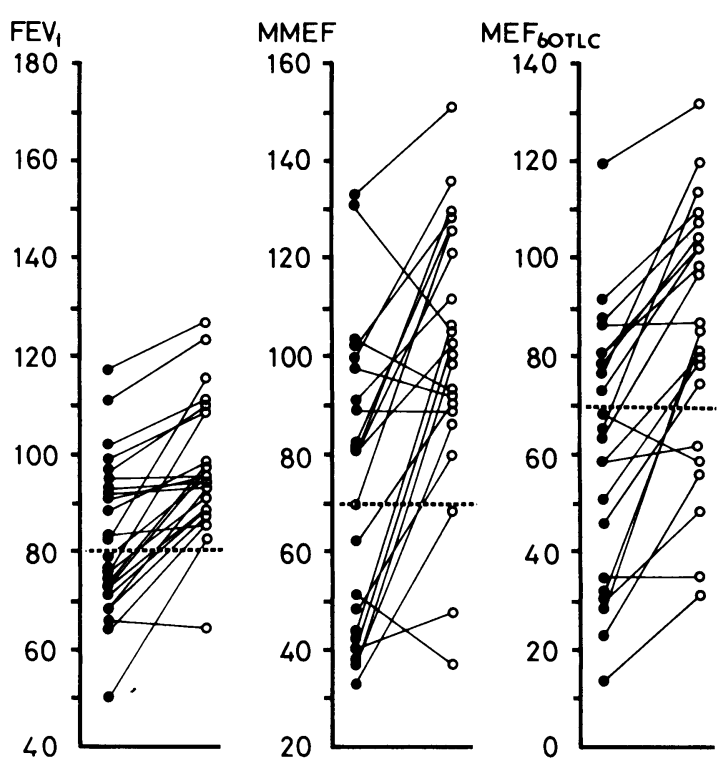

Individual $\mathrm{FEV}_{1}, \mathrm{MMEF}$, and $\mathrm{MEF}_{60 \mathrm{TLC}}$ values before (O) and after (O) bronchodilatation expressed as percentages of expected mean values. Broken lines represent -2 $\mathrm{SD}$ of estimated mean. (MMEF and $\mathrm{MEF}_{60 \mathrm{TLC}}$ measured in only 22 children.)

Our results indicate that asthma should not be regarded as cured when there is a combination of a long, symptom-free history and standard spirometric values within the normal range. Comparable data are scarce, since most authors ${ }^{1-3}$ have described respiratory function after relatively short symptom-free periods. Hill et $a l^{18}$ found frequency-dependence of compliance in three adolescents who had been free of overt wheezing for seven years or more. Clinical and epidemiological studies ${ }^{19-21}$ have also indicated that chronic childhood respiratory disease may relapse after many years without symptoms, and that paediatric respiratory illness is an important risk factor in the development of obstructive airways disease in adult life. This leads us to state the following conclusions and recommendations.

Children and adolescents with a history of asthma in whom all symptoms have disappeared should not be considered to be cured unless all bronchial obstruction has disappeared. They should be checked regularly by their general practitioner or at school medical examinations. As reliable equipment for $\mathrm{MEF}_{25 \mathrm{FVC}}$ and $\mathrm{MEF}_{50 \mathrm{FVC}}$ measurements may now be obtained

\begin{tabular}{|c|c|c|c|c|c|}
\hline & $\mathrm{FEV}_{1} \geqslant 80 \% \mathrm{EMV}$ & $\mathrm{MMEF} \geqslant 70 \% \mathrm{EMV}$ & $\mathrm{MEF}_{60 \mathrm{TLC}} \geqslant 70 \% \mathrm{EMV}$ & $\mathrm{MEF}_{50 \mathrm{FVC}} \gg 70 \% \mathrm{EMV}$ & $\mathrm{MEF}_{25 \mathrm{FVC}}>70 \% \mathrm{EMV}$ \\
\hline No $(\%)$ of children $(\mathrm{n}=56)$ & $40(71)$ & $31(55)$ & $19(34)$ & $31(55)$ & $16(29)$ \\
\hline
\end{tabular}

${ }^{*}$ In all children $\mathrm{FEV}_{1} / \mathrm{VC} \geqslant 70 \%$.

TABLE II-Proportions of asthmatic children* in symptom-free period of at least one week having respiratory function measurements greater than or equal to given percentages of estimated mean values (EMVS) - that is, above lower limit of normal range 
at a reasonable cost the best measurement for routıne determination is $\mathrm{MEF}_{25 \mathrm{FVC}}$. If only a spirometer is available, however, the best measurement is MMEF. Bronchial obstruction may be confirmed by the reaction to bronchodilatation. This can be easily determined after inhaling one puff of a $\beta$-sympathomimetic aerosol, which, if inhaled correctly, has a bronchodilating effect equal to that of thiazinamium. ${ }^{22}$ Young people with apparent bronchial obstruction should be considered to be potentially at risk of obstructive lung disease in adult life. They should therefore be prevented from smoking, receive prompt treatment for eventual bronchial obstruction and respiratory infections, and be given adequate vaccination schedules, particularly for influenza.

\section{References}

${ }^{1}$ Cade, J F, and Pain, M C F, Australian and New Zealand Fournal of Medicine, 1973, 3, 545.

2 Levison, H, et al, Pediatric Clinics of North America, 1974, 21, 951.

3 Palmer, K N V, and Kelman, G R, British Medical fournal, 1975, 1, 485.

${ }^{4}$ Higgins, M W, and Keller, J B, American Review of Respiratory Diseases, 1973, 106, 873

5 Sobol, B, Park, S S, and Emirgil, C, American Review of Respiratory Diseases, 1973, 107, 753.
${ }^{6}$ Ingram, R H, and Schilder, D P, fournal of Applied Physiology, 1966, 21, 1821.

${ }^{7}$ Mead, J, et al, fournal of Applied Physiology, 1967, 22, 95.

${ }^{8}$ Zapletal, A, Paul, T, and Samánek, M, Ceskoslovenská Pediatrie, 1976, 31, 532 .

${ }^{9}$ Kerrebijn, K F, Hoogeveen-Schroot, H C A, and van der Wal, M C, Acta Paediatrica Scandinavica, 1977, suppl No 261, p 62, table 12

${ }^{10}$ Leeder, S R, et al, Bulletin Européen de Physiopathologie, 1977, 13, 249.

11 Löwenberg, A, thesis, 1959, p 131.

12 Bouhuys, A, in Airway Dynamics, Physiology and Pharmacology, ed A Bouhuys, p 263. Springfield, Illinois, Charles Thomas, 1970.

13 Orehek, P, and Gayrard, P, Bulletin Européen de Physiopathologie, 1976 $12,565$.

14 Zapletal, A, et al, Pediatrics, 1971, 48, 64.

15 Olive, J T, and Hyatt, R E, American Review of Respiratory Diseases, $1972,106,366$.

${ }^{16}$ Hill, D J, et al, Archives of Disease in Childhood, 1972, 47, 874.

${ }^{17}$ Cooper, D M, et al, American Review of Respiratory Diseases, 1974, 109, 519.

${ }^{18}$ Hill, D J, Landau, L I, and Phelan, P D, American Review of Respiratory Diseases, 1972, 106, 873

19 Burrows, B, Knudson, R J, and Lebowitz, M D, American Review of Respiratory Diseases, 1977, 115, 751 .

20 Blair, H, Archives of Disease in Childhood, 1977, 52, 613.

${ }^{21}$ Colley, J R T, Douglas, J W B, and Reid, D D, British Medical fournal, 1973, 3, 195.

22 Koster, K, and Kerrebijn, K F, unpublished data.

(Accepted 18 fanuary 1978)

\title{
Intellectual impairment in chronic renal failure
}

\author{
A ENGLISH, R D SAVAGE, P G BRITTON, M K WARD, D N S KERR
}

British Medical fournal, 1978, 1, 888-890

\section{Summary}

In a dialysis centre with a high tap water aluminium content and a known high incidence of dialysis encephalopathy, 29 patients undertaking regular home dialysis, without clinical evidence of encephalopathy, were studied with a battery of psychological tests that have proved useful in detecting early organic intellectual deterioration in other conditions. Full-scale intelligence quotient, as measured by the Wechsler Adult Intelligence Scale, did not differ significantly from that of the normal population, but the patients showed significant deficiencies in three tests of performance-namely, digit symbol, block design, and picture arrangement.

The ability to acquire new information in relation to performance was impaired and the abnormality increased with time on dialysis. Such tests should be useful in early detection of dialysis dementia at a reversible stage.

\section{Newcastle Area Health Authority (Teaching)}

A ENGLISH, Msc, clinical psychologist (now at Airedale General Hospital, Steeton, W Yorks)

University Department of Psychological Medicine, Newcastle upon Tyne NE1 4LP

R D SAVAGE, DSC, FBPSs, senior lecturer (now professor of psychology, Murdoch University, Perth, W Australia)

P G BRITTON, PHD, ABPSS, lecturer

University Department of Medicine, Newcastle upon Tyne NE1 4LP $M$ K WARD, MB, MRCP, lecturer

D N S KERR, MSC, FRCP, professor

\section{Introduction}

Home haemodialysis requires skill, concentration, alertness, and conscientiousness. We rate it in the same class as learning to drive and maintain a car. Not all patients in renal failure can acquire the necessary skills, and about a third of the highly selected group who are accepted for treatment in the UK are never asked to do so. It is crucially important that those who do undertake their own treatment should maintain their intellectual capacity. They face the universal hazard of aging plus several neurological complications of renal failure, ${ }^{1}$ of which the most important is dialysis encephalopathy. ${ }^{2-12}$ This syndrome is usually recognised when the patient develops speech disturbance, apraxia, myoclonus, or fits. By that time home dialysis is already hazardous and the patient doomed to progressive and usually fatal disease. Few patients who reach this stage survive; improvement after transplantation has been recorded in an isolated case, ${ }^{13}$ and two of our patients stopped deteriorating after successful grafts, but in most cases the disease progresses to its lethal conclusion despite good renal function.

In several of our 17 patients with this disease, personality change and intellectual impairment preceded overt features of the illness but were recognised only retrospectively. ${ }^{7}$ Investigation of one early case showed that the intellectual deficit had been seriously underestimated by the clinicians in charge. We therefore undertook a formal study of intellectual functioning in a group of patients who were at serious risk of developing dialysis encephalopathy but had no evident features of the syndrome to see whether early dementia was present.

\section{Patients and methods}

Twenty-nine patients ( 15 men and 14 women) attending the followup clinic for home haemodialysis were referred for intellectual assessment. The first few were chosen because of suspected difficulties with 